\section{Margens do mundo: a periferia nas teorias do}

\section{contemporâneo*}

\begin{abstract}
RESUMO
0 propósito deste trabalho é discutir o conceito de periferia a partir da moldura teórica dos Estudos Culturais contemporâneos. Se na contemporaneidade não há mais dentro e fora, em que lugar ficaria a periferia? Pode-se, ainda, falar de fronteiras, de lugares, de identidades? Se é certo que há uma crise de centralidade, que há um processo de descentramento em curso, é certo também que essa crise afeta e modifica a própria idéia de periferia. Temos, pois, uma crise (ou um conjunto de crises) que precipita um jogo de graus e intensidades, de hibridismo, e artificialidade. A cultura contemporânea compõe a operacionalização do jogo. Este artigo vai, precisamente, discutir alguns dos mecanismos e reflexos dessa operacionalização no âmbito do que se convenciona chamar de "cultura periférica".
\end{abstract}

\section{ABSTRACT}

The objective of this text is to discuss the concept of "periphery" using contemporary theories of cultural studies, taking into account the obsolescence of notions such as "inside" and "outside" and the descentering of the subject, emphasising instead concepts such as gaming, hybridism and artificiality in relation to the idea of "peripheral culture".

\section{PALAVRAS-CHAVE (KEY WORDS)}

- Estudos Culturais (Cultural studies)

- Contemporaneidade (Contemporaneity)

- Cultura periférica (Peripheral culture)

\section{Angela Prysthon}

Doutora em Teoria Crítica e Estudos Hispânicos e Latino-Americanos pela Universidade de Nottingham, Inglaterra, e Professora da Universidade Federal de Pernambuco
(...) então o lado mais positivo da cultura global revelaria a possibilidade de uma encenação, por mais fugaz que seja, da diferença singular dentro da totalidade. Esses sonhos singulares não são apenas os sonhos dos posseiros urbanos de Buenos Aires e das feministas de La Morada, dos homossexuais americanos ou dos funda-mentalistas muçulmanos, dos líderes guerrilheiros neozapatistas ou dos cyberpunks alemães, dos greenheads catalães, dos roqueiros galegos ou dos praticantes do $S$ \& $M$ em Bangcoc: eles são também os sonhos dos intelectuais dos estudos de área acadêmicos, enquanto resistem a se recon-verter em intelectuais corporativos no próprio instante de sua absorção à universidade global. (Moreiras, 2001, p.91)

A PRODUÇÃo CULTURAL da periferia e o debate sobre ela têm consolidado uma tendência na teoria crítica: o discurso da diferença estabelece uma espécie de política das minorias. As diferenças culturais precipitam um imperativo para o teórico da cultura, que é preparar uma moldura conceitual que redefina o papel das minorias, dos subalternos, dos "deserdados da terra" (lembrando Fanon), do que era chamado de Terceiro Mundo na reordenação "global" da cultura. Podemos ver no corpus dos Estudos Culturais contemporâneos e das teorias pós-colonialistas as análises mais agudas dos processos dessa reordenação.

Os Estudos Culturais e o póscolonialismo reafirmam, como antes as 
teorias e políticas terceiro-mundistas, mas de modo muito mais articulado teoricamente, o papel do periférico na História e a própria História periférica. No caso da teoria pós-colonial especificamente, vê-se uma empresa de descolo-nização, mas não a descolonização concreta (algo que já foi mais ou menos realizado) das lutas armadas e acordos militares, mas a descolonização da História e da teoria, uma abordagem de fato alternativa do Ocidente. De teoria estritamente relacionada com as ex-colônias de língua inglesa a uma abordagem de muito maior escopo, os estudos pós-coloniais reinserem o debate da identidade nacional, da representação, da etnicidade, da diferença e da subalternidade no centro da história da cultura mundial contemporânea.

Comentando a obra de Gayatri Chakravorty Spivak (uma das mais destacadas representantes e simultaneamente críticas da teoria póscolonial), Robert Young considera a classificação de subalterno tanto para a historiografia produzida pelo "Outro" como o sujeito que a produz.

O historiador subalterno (o subal-ternista) não apenas localiza instâncias históricas de insurgência, mas também se alinha à subalternidade como uma estratégia para "levar a histo-riografia hegemônica a uma crise" - o que resulta numa boa descrição da estratégia de orientação do próprio trabalho de Spivak. (Young, 1990, p.160)

Ou seja, ao contrário da antropologia clássica ou da historiografia tradicional, a teoria pós-colonial e os Estudos Culturais periféricos poderiam representar a periferia, mais do que isso - já que o pós-colonialismo contesta uma já ultrapassada concepção de representação -, é a própria voz do subalterno que está em jogo. A reescritura periférica da História, ou a desconstrução do Ocidente feita pelos Estudos Culturais contemporâneos e pelo pós-colonialismo, portanto, implica um constante ataque à hegemonia ocidental e, se não uma completa inversão, a reacomodação do cânone cultural, o descentramento anunciado pelas teorias pós-modernas, enfim.

As zonas de contato entre "Primeiro" e "Terceiro" Mundos, pois, vão se multiplicando nas duas regiões e, como seria de se esperar, no destroçado "Segundo". A existência de bolsões de "Terceiro Mundo" no "Primeiro Mundo" e seu contrário, o "Primeiro Mundo" no "Terceiro Mundo", são não apenas a confirmação da idéia do Espaço Híbrido, como também uma condição sine qua non do capitalismo transnacional e o sinal de que um "mundo" somente está cada vez mais parecido na sua diversidade. Justamente no espaço intersticial, no fluido território intermediário, nessa zona de negociação entre "mundos", é que está localizado o arcabouço cultural que serve de objeto para a teoria póscolonial e o instrumental teórico para analisá-lo. Chegamos ao entrelugar.

\begin{abstract}
A crítica formada nesse processo de enunciação de discursos de dominação ocupa um espaço que não está nem dentro nem fora da história do domínio ocidental, mas numa relação tangencial com ele. É o que Homi Bhabha chama de in-between, entre-lugar, uma posição híbrida da prática teórica, ou o que Gayatri Chakravorty Spivak denomina catacrese; "a reversão, o deslocamento e a posse do aparato dos códigos valorativos". (Prakash, 1992, p.8)
\end{abstract}

O lugar do periférico na configuração da cultura contemporânea e na crítica, análise e teoria dessa cultura, portanto, está muito diferenciado em contraste com as disciplinas mais tradicionais. É um ponto de observação privilegiado no sentido da 
multiplicidade desse espaço intermediário. Mesmo que tantas outras teorias e estéticas já houvessem problematizado conceitos como representação, identidade, outridade, hibridismo, colonização, Ocidente, Oriente; com os Estudos Culturais e com o pós-colonialismo esses elementos são colocados num marco de referências que, ao invés de simplesmente inverter ou descartar termos e hierarquias, vai questioná-los na sua essência e na sua malha de inter-relações, vai pensar as condições de possibilidade, continuidade e utilidade da sua construção.

A pós-colonialidade representa uma resposta a uma necessidade genuína: a necessidade de superar a crise de entendimento produzida pela inabilidade das velhas categorias em dar conta do mundo. (Dirlik, 1994,p. 352)

O que não corresponde a dizer que o pós-colonialismo e os Estudos Culturais são teleologicamente positivos em relação à pós-modernidade ou às micropolíticas de final de milênio. Não se trata de simplesmente ser ingenuamente "otimista" por causa da globalização, por causa do hibridismo cultural e por uma suposta superação da experiência colonial, ou, no campo da estética, de tentar inverter os valores do cânone à moda da "antropofagia" brasileira modernista, por exemplo, assim proclamando a superioridade do periférico, do "terceiro-mundista". Não é tão simples.

Porque, sim, de certa forma, a pósmodernidade toma ao pé da letra e leva a extremos uma interpretação conservadora da modernidade: a racionalização teleológica, a tecnologia e a modernização passando por cima dos ideais libertadores do lluminismo. As formas culturais produzidas nesse esquema teriam que se adaptar ao declínio da arte tradicional e das hierarquias marcadas entre os diversos tipos de cultura. Mas em outro sentido, o contemporâneo - e os Estudos Culturais e a teoria pós-colonial trabalham justamente com essa possibilidade - também é uma superação radical desse esquema - não uma inversão -, na medida em que emergem as políticas da diferença e da subalternidade:

Há mesmo uma convicção crescente de que a experiência afetiva da margi-nalidade social - como ela emerge em formas culturais nãocanônicas - transforma nossas estratégias críticas. Ela nos força a encarar o conceito de cultura exteriormente aos objets d'art ou para além da canonização da "idéia" de estética, a lidar com a cultura como produção irregular e incompleta de sentido e de valor, freqüentemente composta de demandas e práticas incomensuráveis, produzidas no ato de sobrevivência social. (Bhabha, p. 240)

Exatamente no foco de todo repensar sobre a subalternidade e suas relações com a identidade nacional e as políticas de superação do subdesenvolvimento, vamos nos encontrar novamente com a dualidade centro-periferia. Neste sentido, o debate sobre o pós-moderno serve, apesar da multiplicidade de "encarnações", propósitos e definições, fundamentalmente para designar a crise de centralidade pela qual passa o Ocidente. Insistimos que tal crise é a pedra de toque da teoria contemporânea, que vai repensar as "regras do jogo" da diferença cultural a partir do descentramento pós-moderno. O descentramento vai ser muitas vezes tomado como uma inversão de valores. De repente, as margens passam a centro e o centro à margem, numa celebração catártica das diferenças em desfile.

A singularidade cultural é o campo utópico do subalternista. O subalternista por definição deixa-se permanecer preso à condição 
problemática básica de, ao mesmo tempo, afirmar e abandonar a singularidade cultural. O subalternista precisa afirmar e, em seguida, encontrar e representar - isto é, precisamente não "construir" - a singularidade cultural do subalterno, tida como diferença positiva diante da formação cultural dominante. (Moreiras, 2001, p.198)

Os discursos tecidos num entrelugar (ver mais adiante discussão sobre o termo), as teorias baseadas nas culturas periféricas, as políticas da diferença apontam para um entrelaçamento entre experiência cultural, a prática da crítica e o terreno da política, para um transbordamento da cultura para fora do campo estético. Vão sugerindo, assim, um campo fortemente marcado pela utopia: a utopia dos discursos da heterogeneidade, dos sonhos singulares, de um entrelugar complexo e híbrido. Ou seja, discursos que, num paradoxo sempre intrigante, almejam uma certa harmonia nas diferenças. E assim como a utopia depende da impossibilidade da sua realização, o teórico periférico (e da periferia), do entrelugar, sabe que está permanentemente denunciando a impraticabilidade de seu projeto.

\section{O entrelugar: a esfera do além}

Homi Bhabha, logo na introdução de $\mathrm{O}$ Local da Cultura, afirma que o tropo dos nossos tempos é colocar a questão da cultura na esfera do além, onde estaríamos vivendo "nas fronteiras do 'presente', para as quais não parece haver nome próprio além do atual e controvertido deslizamento do prefixo 'pós"'. (Bhabha, 1998, p.19) A esfera do além não indica uma superação do passado ou uma escalada rumo ao futuro, mas um lugar e um momento de trânsito, um processo contínuo que produz incessantemente as peças do jogo mencionado acima.

Assim,

Bhabha vai começando a definir um dos tours de force de sua teoria, o que ele chama de in-between, o "entrelugar" da cultura, ponto que estaria precisamente nessas fronteiras e que simultaneamente articularia as temporalidades e as espacialidades do contemporâneo: tempos e espaços múltiplos nos quais vão se confrontar permanentemente presente e passado, modernização e tradição, tecnologia e natureza e nos quais vão sendo desafiadas "as expectativas normativas de desenvolvimento e progresso" (Idem, p.21). Ao promover esse confronto, a noção de entrelugar traz à tona uma espécie de reordenação (política e cultural) do mundo, um remapeamento baseado na superação de vários dos pilares da modernidade cultural, como a dialética da dependência cultural, a distinção entre original e cópia, a oposição entre tradição e novidade.

O conceito de entrelugar vai ser particularmente relevante para entender o que acontece com a contemporaneidade periférica, até porque, em certa medida, ele surge dos embates vividos nas margens dos cânones culturais. Embora a idéia de periferia sugira uma centralidade já proclamada obsoleta, ao mesmo tempo a cultura periférica emerge no contemporâneo como o instrumento principal de desestabilização do centro. Silviano Santiago, usando o termo antes de Bhabha, aliás, já definia o entrelugar como recuperação suplementar da tradição européia, como discurso utópico do "eterno retorno em diferença" (Santiago, 1989, p.109), como possibilidade de repensar as vanguardas em relação à tradição, como ponto de partida para a constituição de um pensamento que desconstrua a história da dependência. Em "O entrelugar $^{1}$ do discurso latino-americano" (1978), Silviano Santiago lança mão da história colonial e das relações entre indígenas e catequizadores para chegar a uma proposição talvez por demais generalizante 
para a contemporaneidade cultural da América Latina.

Entre o sacrifício e o jogo, entre a prisão e a transgressão, entre a submissão ao código e a agressão, entre a obediência e a rebelião, entre a assimilação e a expressão, - ali, nesse lugar aparentemente vazio, seu templo e seu lugar de clandestinidade, ali, se realiza o ritual antropófago da literatura latino-americana. (Santiago,1978, p.28)

O entrelugar para Santiago explicaria fundamentalmente a diferença periférica e subalterna (Iatino-americana) como devendo ao mesmo tempo às idéias de progresso e modernidade - cumprindo uma espécie de pacto com a História ocidental - e à incorporação de elementos alternativos das minorias lingüísticas, sociais e culturais que compõem os tempos e espaços multifacetados das culturas da periferia. Com essa mescla, com essa soma imaginária de culturas e imaginários, a América Latina representaria desde o período de colonização não somente esses processos de hibridização em si, mas a sua autoconsciência:

A maior contribuição da América Latina para a cultura ocidental vem da destruição sistemática dos conceitos de unidade e de pureza: estes dois conceitos perdem o contorno exato do seu significado, perdem o seu peso esmagador, seu sinal de superioridade cultural, à medida que o trabalho de contaminação dos latino-americanos se afirma, se mostra mais e mais eficaz. (Santiago, 1978, p.18)

A sua proposta, contudo, revela-se aplicável não só à cultura latino-americana, mas ao que ele chama de "cultura dominada" em geral; constituindo então a desconstrução da hierarquia colonizadorcolonizado.
Paradoxalmente, o texto descolonizado (frisemos) da cultura dominada acaba por ser o mais rico (não do ponto de vista de uma estreita economia interna da obra) por conter em si uma representação do texto dominante e uma resposta a esta representação no próprio nível da fabulação, resposta esta que passa a ser um padrão de aferição cultural da universalidade tão eficaz quanto os já conhecidos e catalogados. (Santiago, 1982, p.23)

\section{Identidades fraturadas e hibridismo}

O entrelugar seria, portanto, um espaçotempo em essência periférico, seria o palco por excelência para encenar os múltiplos embates político-culturais da contemporaneidade. A partir da delimitação desse espaço/tempo-múltiplo do entrelugar, fica claro que uma vertente importante no discurso da teoria crítica da cultura tem sido a tematização do descentramento identitário ocorrido na pós-modernidade. Um dos clichês mais recorrentes da teoria contemporânea parece ser o da quebra das identidades (sejam elas culturais, nacionais ou mesmo individuais). A discussão sobre a identidade vai ser fundamental para a própria constituição do conceito de pósmodernidade.

O pós-moderno (pós-modernidade) é relevante para o debate sobre as culturas periféricas justamente porque oferece alternativas para a incessante busca de "identidade" na periferia mundial. Tanto as concepções estritamente estéticas e estilísticas como as teorias mais globalizantes e completas do panorama social e cultural pós-moderno trazem a idéia de descentramento no seu bojo.

Ora, a dualidade margens-centro sempre foi um dos principais componentes da identidade periférica e a quebra (ou mesmo apenas a aparente quebra...) desta 
dualidade coincide com a emergência do questionamento deste tipo de dicotomia pela cultura, arte e teoria dos países ditos subdesenvolvidos. Para essas regiões, principalmente como construção simbólica em permanente intercâmbio com o Ocidente (ou o "Nordocentro" desenvolvido), é inquestionável a importância e a recorrência a termos como metrópole, cópia, simulacro, deslocamento, nação, alteridade...

Presenças por vezes incômodas que o pensamento pós-moderno propôs-se a desafiar, e que a teoria periférica também tem desconstruído através de uma crítica às formas mais tradicionais de se colocar teoricamente o problema da "diferença".

Em última instância, a categoria pós-moderno beneficiou um viés de interpretação da identidade periférica que se não é essencialmente novo, ao menos parece mais aberto, polivalente que os anteriores esquemas binários (metrópole/ colônia, europeu/indígena, etc...).

Um viés que se caracteriza pela utilização positiva do termo híbrido e suas derivações: as identidades periféricas vão sendo definidas e discutidas por meio da noção de hibridismo.

Se no século XIX, híbrido, hibridismo e hibridização eram palavras e noções quase que exclusivamente circunscritas ao âmbito da biologia e da antropologia e carregadas de um sentido extremamente negativo, no final do século $X X$ ocupou mais e mais destaque nas Ciências Humanas, Letras e Estudos Culturais.

Um relevo que atinge seu ápice na teoria pós-colonial, embora uma das primeiras áreas além da biologia e antropologia a focalizarem o hibridismo tenham sido a Filologia e a Lingüística, primeiro superficialmente no século XIX e com mais profundidade e especificidade depois na obra de Bakhtin (Young, 1995, pp.6-20).

Na América Latina, o trabalho de Néstor García Canclini (1990), por exemplo, tem especial ressonância na teoria pós- moderna, pois redimensiona o híbrido como o dominante mais básico e geral da cultura latino-americana contemporânea.

O Estado Híbrido passa a denominar o caráter múltiplo da cultura contemporânea mundial, em especial a de regiões marcadas pela existência de várias identidades ou "origens": ameríndia, européia, africana, asiática...; várias temporalidades: pré-industrial, moderna, tecnológica; e pela possibilidade de abolição das fronteiras entre cultura erudita, popular e de massas.

Canclini analisa detalhadamente como se deu um esgotamento nos aparatos do Estado e como as políticas culturais tradicionais se tornaram obsoletas diante dessa hibridização.

Como o entrelugar, a idéia do Estado Híbrido pode substituir o pós-moderno em algumas abordagens das teorias culturais mais recentes, na medida em que aponta o hibridismo inerente das identidades periféricas (em especial das sociedades latino-americanas) como uma espécie de antecedente e pressuposto para a constituição dos conceitos de pluralismo, multiculturalismo e pós-moderno na "metrópole".

Diferenças em desfile

Se o entrelugar e o híbrido são conceitos que recolocam o problema das culturas periféricas no âmbito teórico, o multiculturalismo (tal como delineado a partir da década de 80) vai ser a concretização - e em alguns momentos deturpação - de alguns dos componentes desses conceitos no território da produção cultural propriamente dita.

O multiculturalismo poderia ser brevemente definido como o momento em que a cultura periférica não apenas passa a ser percebida pela cultura central, como passa a ser consumida na metrópole; o ponto em que a diferença cultural passa a ser encarada como estratégia de marketing. A "diferença" torna-se ponto de partida para a integração ao modelo capitalista 
global, especialmente em relação aos bens culturais.

O mercado de cultura mundial abrese, então, ao multiculturalismo e os efeitos de uma cada vez maior presença de bens simbólicos periféricos junto à cultura de massa internacional se fazem sentir em todos os cantos do planeta, especialmente desde o início da década de 80. William Rowe e Vivian Schelling constatam que:

Todos os significados estão disponíveis e transferíveis, de Mozart à música folclórica boliviana, de Dallas às telenovelas brasileiras, de hambúrgueres a tacos. A tendência de produtos de diferentes ambientes culturais se mesclarem numa escala global está acelerando enquanto o século caminha para o fim. (Rowe e Schelling, 1992, p.1)

Cabe lembrar que o multiculturalismo, como fenômeno ligado à disseminação em massa das culturas locais, não pode ser visto sem reservas: mais do que iniciativas independentes "nacionais \& populares" ou do que uma utópica rearticulação do local em escala global, ele também é um jogo de interesses recíprocos por parte de empresas, grupos políticos e indivíduos. Outro receio provocado pela disseminação generalizada de culturas tão diversas e peculiares é de que ela tenha um efeito homogeneizador sobre essas culturas. Alguns exemplos rápidos: passase cada vez mais a consumir o Realismo Mágico já consagrado - e filtrado - pelas academias européias e norte-americana (mais escritores seguidores deste "estilo" aparecem e se parecem); a cozinha étnica vem a ser o que o "Ocidente" quer que essa cozinha étnica seja (sushies, curries, tacos de sabor "internacional"...); a principal preocupação de world musicians se torna adaptar seu trabalho aos ouvidos norte-americanos dos big bosses das gravadoras.

Admitindo todas essas limitações
- mercadológicas, estéticas, políticas - das diferenças em desfile do multiculturalismo contemporâneo, é inegável que algo mudou no cânone ocidental. E, como já foi pressentido no início deste texto, o reflexo dessas transformações vai ser especialmente intenso no debate teórico. O multiculturalismo vai ultrapassar as fronteiras de um mercado cultural de massas mais sofisticado e acaba por tomar conta também da academia - principalmente dos círculos angloamericanos - como fenômeno pósmoderno (visto assim como conseqüência de um dos traços da pós-modernidade - o descentramento). Por um lado, o debate sobre multiculturalismo resvalou muitas vezes para uma oposição extrema entre conservadores e radicais multiculturalistas. Por outro, foi reaceso o interesse cultural no Outro para além da psicologia, antropologia, lingüística e etnografia. O Outro que emerge no final dos anos 80 nos cursos universitários europeus e norte-americanos é, sobretudo, o "Terceiro Mundo" (claro, também a mulher, os gays e lésbicas, os negros...). E em especial assuntos concernentes às relações entre "Império" e "Colônias", ou "ex-colônias". As teorias culturais contemporâneas estão indissoluvelmente impregnadas por esse interesse pelo Outro, pela diferença, interesse que tem diversas naturezas ("científicas", culturais, mercadológicas...) e onde todas podem conviver numa mesma teoria e num mesmo teórico.

É uma espécie de dever do crítico de cultura, do teórico da contemporaneidade, resgatar o projeto do discurso da diferença, vendo no entrelugar - concebido não mais como inversão do cânone, como "privilégio" da periferia - as possibilidades de diálogo entre culturas. Seria o ato transgressor (no melhor sentido) da tradução cultural, como a define Bhabha.

Se hibridismo é heresia, blasfemar é sonhar. Sonhar não com o passado ou o presente, e nem com o presente contínuo; não é o sonho nostálgico da tradição nem 
o sonho utópico do progresso moderno;

é o sonho da tradução, como sur-vivre, como "sobrevivência", como Derrida traduz o "tempo" do conceito benjaminiano da sobrevida da tradução, o ato de viver nas fronteiras (Bhabha, 1998, p.311) .

\section{Notas}

* Este trabalho forma parte de reflexões mais gerais acerca da natureza da periferia na cultura contemporânea e foi enriquecido pelos debates nas reuniões da pesquisa "Representações Urbanas: Recife e suas expressões mi-diáticas" do grupo Comunicação, Tecnologia e Estudos Culturais do Programa de Pós-graduação em Comunicação da UFPE.

1 Na primeira aparição do termo, em Uma literatura nos trópicos (1978), Santiago utilizava o hífen. Já nos ensaios subseqüentes dos volumes Vale quanto pesa (1982) e Nas malhas da letra (1989), ele passa a abolir o hífen de entrelugar.

\section{Referências}

BHABHA, Homi K. O local da cultura. Belo Horizonte: Editora da UFMG, 1998.

DIRLIK, Arif. "The Postcolonial Aura: Third World Criticism in the Age of Global Capitalism", Critical Inquiry 20 (1994), pp.328-356.

CANCLINI, Néstor Garcia. Culturas Hibridas: Estrategias para entrar y salir de la modernidad. Mexico D.F.: Grijalbo, 1990.

HARDT, Michael. "A sociedade mundial de controle" in ALLIEZ, Éric (org.), Gilles Deleuze: Uma vida filosófica. São Paulo: Editora 34, 2000.

MOREIRAS, Alberto. A exaustão da diferença. A política dos estudos culturais latino-americanos. Belo Horizonte: Editora da UFMG, 2001.

PRAKASH, Gyan. "Postcolonial Criticism and Indian Historiography", Social Text 31-32 (1992), pp.6-18.
ROWE, William e SCHELLING, Vivian. Memory and Modernity. Popular Culture in Latin America. London: Verso, 1992.

SANTIAGO, Silviano. "Nas malhas da letra. São Paulo: Companhia das Letras, 1989.

Uma literatura nos trópicos. São Paulo: Perspectiva, 1978.

. Vale quanto pesa. Rio de Janeiro: Paz e Terra, 1982.

YOUNG, Robert. Colonial Desire. Hybridity in Theory, Culture and Race. London/New York: Routledge, 1995.

White Mythologies. Writing History and the West. London/New York: Routledge, 1990. 